\title{
Radical Radiation Therapy for Radiation-Induced Angiosarcoma with Local Control
}

\author{
Tsutomu Ikenohira Kenta Konishi Masanori Hirata Keiichi Ohira \\ Katsumasa Nakamura
}

Department of Radiation Oncology, Hamamatsu University School of Medicine, Shizuoka, Japan

\section{Keywords}

Radiation-induced angiosarcoma $\cdot$ Radical radiotherapy-alone $\cdot$ Japanese

\begin{abstract}
Angiosarcoma is believed to be refractory to radical radiotherapy. Although no effective treatment for radiation-induced angiosarcoma has been established, surgery is generally chosen. We report a case of unresectable radiation-induced angiosarcoma after breast cancer surgery that responded remarkably to radical radiotherapy alone. A 78-year-old Japanese female had a large mass in her right breast that was diagnosed as angiosarcoma after biopsy and considered to be a radiation-induced angiosarcoma because the patient had been treated with postoperative irradiation to the right breast cancer 8 years earlier. There were no findings suggestive of lymphadenopathy or distant metastasis. Since the tumor was widely infiltrated to the skin and the muscle layer, radical radiotherapy (total dose $66 \mathrm{~Gy}$ ) was performed. At this radiotherapy completion, the tumor was remarkably reduced, and there were no acute adverse effects except for grade 2 dermatitis. Pazopanib was started after radiotherapy but was discontinued since necrosis of the wound with hemorrhage was observed. External pneumothorax occurred due to the marked tumor shrinkage, but it was cured by conservative care. Although angiosarcoma is well known to be radioresistant, excellent local control may be obtained by radical radiotherapy in some cases. Radiotherapy should be considered as a treatment option in inoperable cases.
\end{abstract}




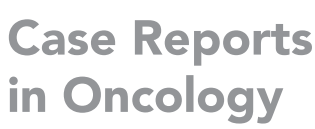

\begin{tabular}{l|l}
\hline Case Rep Oncol 2021;14:1779-1784 \\
\hline DOI: 10.1159/000519596 & $\begin{array}{l}\text { @ 2021 The Author(s). Published by S. Karger AG, Basel } \\
\text { www.karger.com/cro }\end{array}$ \\
\hline
\end{tabular}

Ikenohira et al.: Radical Radiation Therapy for Radiation-Induced Angiosarcoma with Local Control

\section{Introduction}

Angiosarcoma of the breast is rare and is also known as radiation-induced cancer; its reported frequency after postoperative radiotherapy for breast cancer is $0.09 \%-0.16 \%$ [1]. Radiation-induced angiosarcoma is a malignant tumor with poor prognosis. Although no effective treatment for radiation-induced angiosarcoma has been established, surgery is generally chosen. Angiosarcoma is believed to be refractory to radical radiotherapy, sometimes performed as postoperative irradiation [2]. We report a case of unresectable radiationinduced angiosarcoma after breast cancer surgery that responded remarkably to radical radiotherapy alone.

\section{Case Report/Case Presentation}

A 78-year-old Japanese female was referred to our hospital in January 2020 due to a large mass in her right breast. She was diagnosed with right breast cancer (pathology unknown) in 2012. She underwent breast-conserving surgery and axillary dissection followed by radiotherapy (total dose 50 Gy per 25 fractions) and 5 years of hormone therapy administered by her previous physician. In June 2019, approx. 7 years later, she noticed a mass in her right breast within a previously irradiated field. The mass gradually enlarged in size and finally self-destructed. A biopsy revealed with no malignant cells. There was no improvement in her condition even after hormone therapy was resumed, and thus, recurrence of the breast cancer was suspected. After her referral to our hospital, contrast-enhanced CT and MRI revealed a 5 $\mathrm{cm} \times 3 \mathrm{~cm} \times 8 \mathrm{~cm}$ mass in the right breast with invasion to the right pectoralis major muscle (shown in Fig. 1a, b). There were no findings suggestive of lymphadenopathy or distant metastasis. The mass was diagnosed as angiosarcoma after the biopsy and considered to be a radiation-induced angiosarcoma. Since the lesion had widely infiltrated to the skin and the muscle layer, it was considered inoperable. Because of the patient's advanced age, radical radiotherapy without chemotherapy was selected.

In March 2020, three-dimensional conformal radiotherapy was performed. In this case, a mass in the right breast was used as the field. A total dose of 66 Gy per 33 fractions with the shrinkage of the field at 50 Gy was prescribed with tangential irradiation using a LINAC 4 MV $\mathrm{X}$-ray (shown in Fig. 2). The tumor responded well and shrunk at $36 \mathrm{~Gy}$, and the hemorrhage and effusion from the tumor also decreased.

At the termination of the treatment, there were no obvious acute-phase adverse effects with the exception of grade 2 radioactive skin flame, and the tumor was remarkably reduced. In April 2020, pazopanib was started after the radiotherapy was completed. However, it was discontinued in August 2020 because necrosis of the wound with hemorrhage was observed. In September 2020, external pneumothorax due to marked tumor shrinkage was observed. The external chest air was cured by thoracic drainage. In November 2020 , the patient was transferred to a long-term care hospital under best supportive care. There was no local progression or distant metastasis at the time of transfer (shown in Fig. 1c).

\section{Discussion/Conclusion}

Radiation-induced angiosarcoma after breast cancer radiotherapy is rare, but it is one of the possible late adverse effects of radiotherapy and has a poor prognosis. It is reported that there is a peak of onset at $\sim 5-10$ years after radiotherapy [2]. Retrospective studies of small

\section{Karger'}




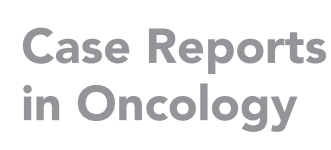

\begin{tabular}{l|l}
\hline Case Rep Oncol 2021;14:1779-1784 \\
\hline DOI: 10.1159/000519596 & $\begin{array}{l}\text { ○ 2021 The Author(s). Published by S. Karger AG, Basel } \\
\text { www.karger.com/cro }\end{array}$ \\
\hline
\end{tabular}

Ikenohira et al.: Radical Radiation Therapy for Radiation-Induced Angiosarcoma with Local Control
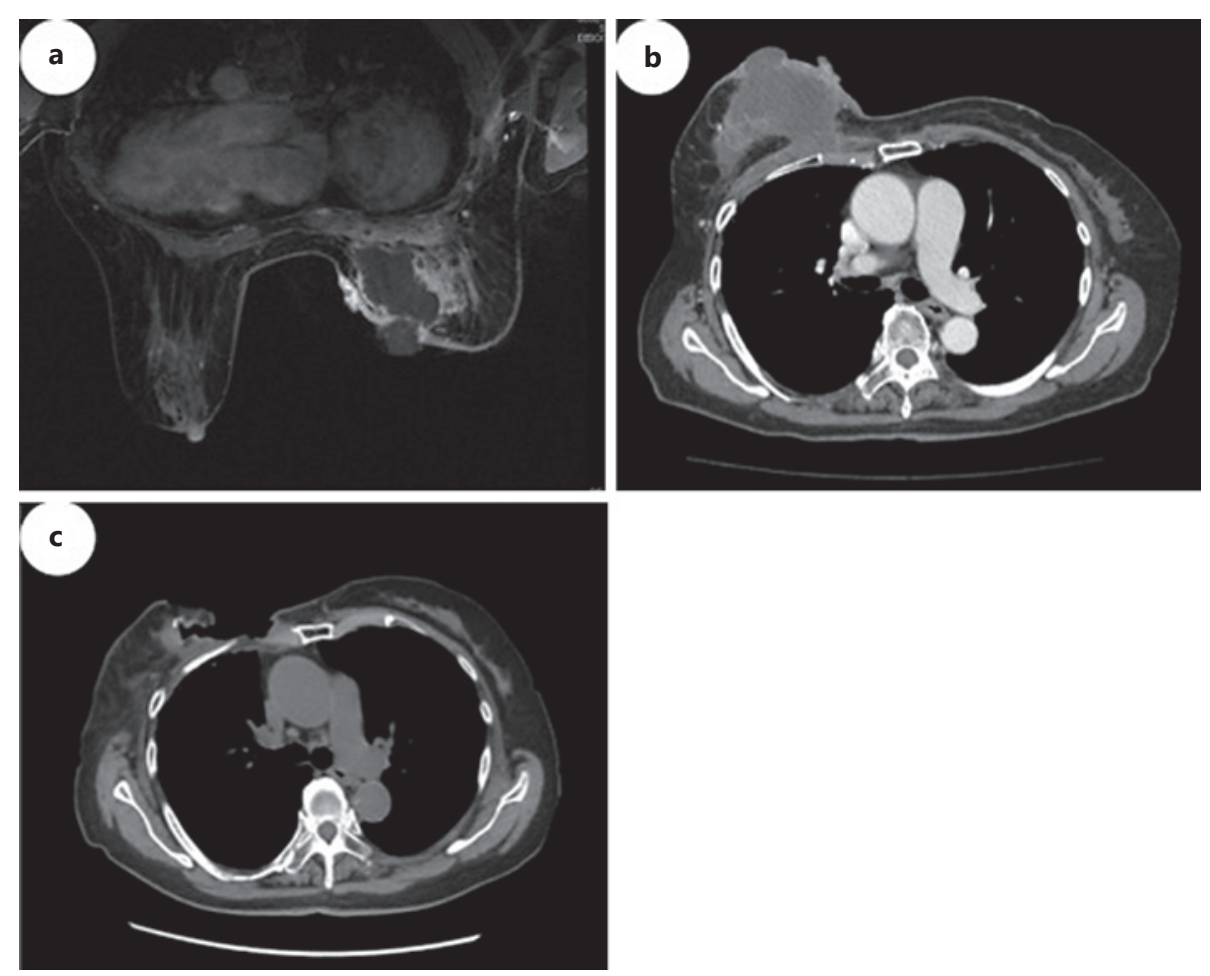

Fig. 1. a, b Contrast-enhanced MRI and CT before radiotherapy showed a $5 \mathrm{~cm} \times 3 \mathrm{~cm} \times 8 \mathrm{~cm}$ mass in the right breast with the invasion to the right pectoralis major muscle. c Plain CT at 4 months after radiotherapy showed that the tumor was remarkably reduced.

case series of secondary breast angiosarcoma after radiotherapy reported that all lesions were in the radiation field [3-5]. In the present case, the tumor also occurred in the irradiation field.

There are few retrospective case reports about treatment for angiosarcoma, and there are no reports with high evidence levels. The first choice for local disease is surgical resection, and chemotherapy may be considered when the risk of distant metastases is present. Postoperative radiotherapy is also considered when there is a high risk of local recurrence [2]. In a systematic review of 222 cases of radiation-induced breast angiosarcoma, Depla et al. [6] reported $57 \%$ as the 5-year local control rate in the group treated with postoperative irradiation, which was better than the 37\% 5-year local control rate in the group treated with surgery alone. However, the 5-year survival rate was $55 \%$ in the combined postoperative irradiation group and $48 \%$ in the surgery-only group, with no significant difference [6].

Generally, because angiosarcoma is believed to be radioresistant, radical radiotherapy has rarely been performed. In addition, radical radiotherapy for radiation-induced hemangiosarcoma has not been indicated because of the potential overdosing of normal tissues [2]. Mark et al. [7] retrospectively analyzed 67 cases of primary angiosarcoma; 56 patients underwent surgery, and 11 patients underwent radiotherapy. Of the 11 patients treated with radiotherapy, the radiation doses varied in the range of 30-70 Gy, and only 1 patient was rendered disease-free. In their systematic review of 222 cases of radiation-induced angiosarcoma after surgery for primary breast cancer, Depla et al. [6] reported that 14 patients who were not medically indicated for surgery or were unresectable were treated with radiotherapy combined with hyperthermia, and 13 of the patients developed local

\section{Karger'}




\section{Case Reports in Oncology}
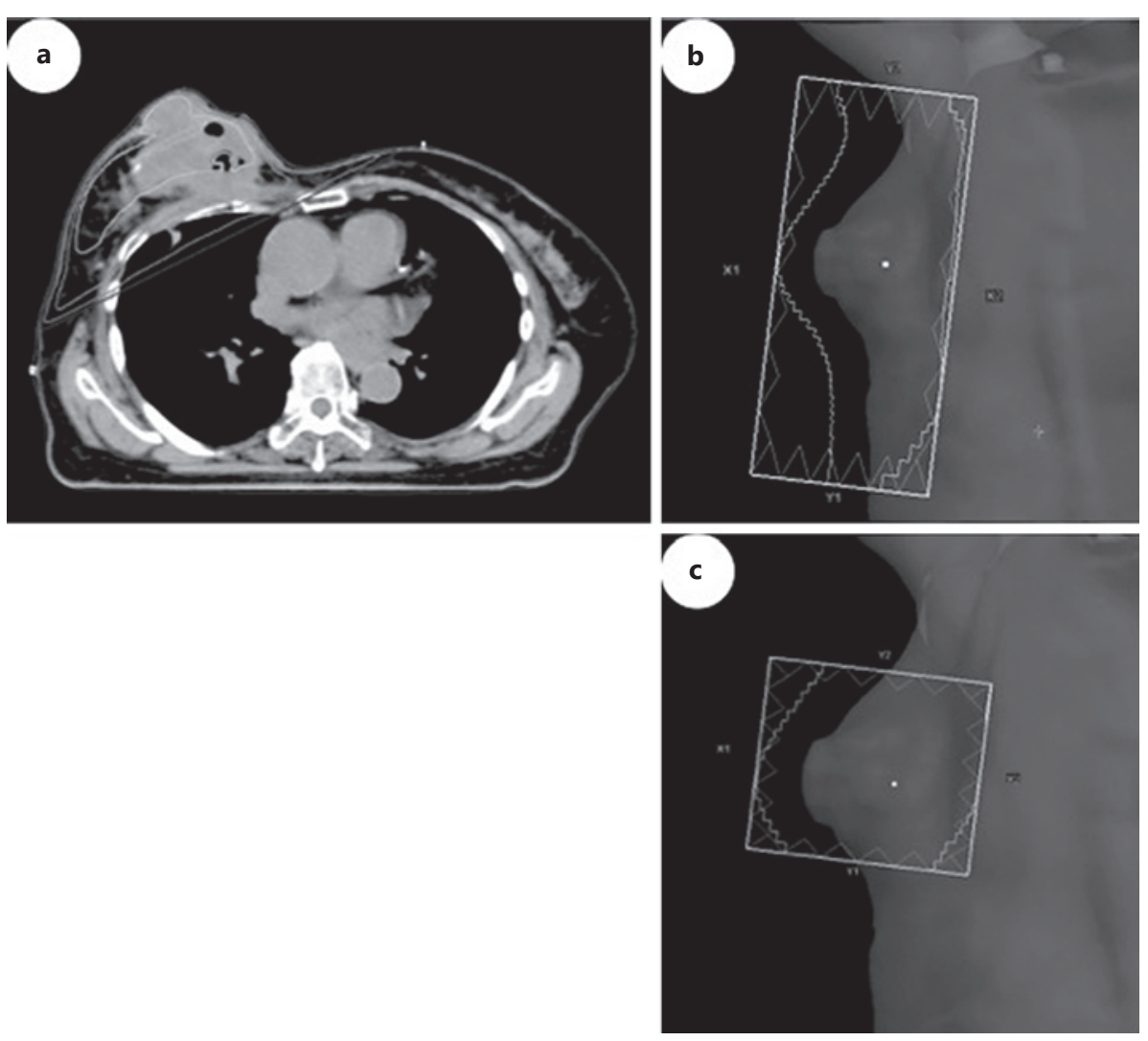

Fig. 2. a Three-dimensional conformal radiotherapy was performed. b, c A total dose of 66 Gy/33 fractions with the shrinkage of the field at 50 Gy was prescribed with tangential irradiation using a LINAC 4 MV X-ray.

recurrence; the radiation doses were not reported. Considering these reports, it may be judged that radiotherapy for radiation-induced angiosarcoma is not the recommended first-line of treatment.

Our literature search revealed few reports of radical radiotherapy-alone re-irradiation for radiation-induced angiosarcoma. In a case report of a patient with radiation-induced angiosarcoma, MaKey et al. [4] reported that palliative treatment with a total dose of 10 Gy per 2 fractions resulted in a major reduction in recurrent disease within and outside the radiation, suggesting that angiosarcoma in some cases may be radiosensitive. The systematic review by Depla et al. [6] also reported that postoperative irradiation after the resection of radiation-induced angiosarcoma improved the local control rate, and interestingly, they reported that the local control rate was $25 \%$ in the patients who received $\leq 45$ Gy compared to those who received $>50 \mathrm{~Gy}$. Our present patient also showed a marked reduction in the size of a huge mass in the chest wall with 66 Gy of irradiation. Angiosarcomas may benefit to some degree from radiation therapy, and such therapy could be considered worth as in aggressive option, at least in inoperable cases.

Regarding re-irradiation to the breast, several articles indicated that the breast may be well-tolerant to re-irradiation. In the RTOG1014 trial, 65 patients with recurrent breast cancer after radiotherapy underwent re-tumor resection and local re-irradiation at 45 Gy per 30 fractions twice daily. The grade 3 or higher adverse effects were tissue fibrosis in only 1 patient $(\leq 2 \%)$ [8]. In their series of 248 patients with unresectable locally recurrent breast cancer after radiotherapy, Linthorst et al. [9] treated the patients with 32 Gy per 8 fractions, 
twice-weekly re-irradiation, and hyperthermia. Grade 3 or higher adverse effects were seen as skin necrosis only in 3 patients (1\%) [9]. Fung et al. [10] reported that among 55 patients with bilateral breast cancer treated with a total dose of 45-50 Gy postoperatively, 14 patients (25\%) had overlapping fields but no serious adverse effects. Deutsch reported that 39 patients with recurrent breast cancer after radiotherapy underwent tumor enucleation and re-irradiation 50 Gy per 25 fractions by an electron beam, and there were no grade 3 or higher side effects [11].

Our patient showed case external pneumothorax as a grade $\geq 3$ adverse effect that might have been caused by the dramatical shrinkage of the tumor. Irradiation methods and doses such as twice daily irradiation have been investigated to reduce the incidence of side effects, but the prescribed dose in this report seems to be within a reasonable dose level, considering the size of the patient's angiosarcoma.

\section{Conclusion}

Although angiosarcoma is radioresistant, excellent local control may be obtained by radical radiotherapy in some cases. Radiotherapy should be considered as one of the treatment options in inoperable cases.

\section{Statement of Ethics}

Written informed consent was obtained from the patient for publication of this case report and any accompanying images. Since this is a case report, it is not required by our regulations.

\section{Conflict of Interest Statement}

The authors have no conflicts of interest to declare.

\section{Funding Sources}

The authors did not receive any funding for this study.

\section{Author Contributions}

All the authors revised the manuscript, approved the manuscript to be published, and agree to be accountable for all aspect of the work in ensuring that questions related to the accuracy or integrity of any part of the work are appropriately investigated and resolved.

\section{Data Availability Statement}

All data generated or analyzed during this study are included in this article. Further inquiries can be directed to the corresponding author. 


\section{Case Reports in Oncology}

\begin{tabular}{l|l}
\hline Case Rep Oncol 2021;14:1779-1784 \\
\hline DOI: 10.1159/000519596 & $\begin{array}{l}\text { ○ 2021 The Author(s). Published by S. Karger AG, Basel } \\
\text { www.karger.com/cro }\end{array}$ \\
\hline
\end{tabular}

Ikenohira et al.: Radical Radiation Therapy for Radiation-Induced Angiosarcoma with Local Control

\section{References}

1 Glazebrook KN, Magut MJ, Reynolds C. Angiosarcoma of the breast. AJR Am J Roentgenol. 2008;190(2):533-8.

2 Young RJ, Brown NJ, Reed MW, Hughes D, Woll PJ. Angiosarcoma. Lancet Oncol. 2010;11(10):983-91.

3 Hadi-Hamou N-S, Lae M, Almeida A, Grange P, Kirova Y, Sastre-Garau X, et al. A transcriptome signature of endothelial lymphatic cells coexists with the chronic oxidative stress signature in radiation-induced postradiotherapy breast angiosarcomas. Carcinogenesis. 2012;33(7):1399-405.

4 McKay MJ, Rady K, McKay TM, Mckay JN. A radiation-induced and radiation-sensitive, delayed onset angiosarcoma arising in a precursor lymphangioendothelioma. Ann Transl Med. 2017;5(6):137.

5 Amajoud Z, Vertongen AS, Weytens R, Hauspy J. Radiation induced angiosarcoma of the breast: case series and review of the literature. Facts Views Vis Obgyn. 2018;10(4):215-20.

6 Depla AL, Scharloo-Karels CH, Jong MAA, Oldenborg S, Kolff MW, Oei SB, et al. Treatment and prognostic factors of radiation-associated angiosarcoma (RAAS) after primary breast cancer: a systematic review. Eur J Cancer. 2014;50(10):1779-88.

7 Mark RJ, Poen JC, Tran LM, Fu YS, Juillard GF. Angiosarcoma. A report of 67 patients and a review of the literature. Cancer. 1996;77(11):2400-6.

8 Arthur DW, Winter KA, Kuerer HM, Haffty BG, Cuttino LW, Todor DA, et al. NRG oncology RTOG 1014: 1 year toxicity report from a phase II study of repeat breast preserving surgery and 3D-conformal partial breast re-irradiation (3D-CRT PBrI) for in-breast recurrence. Int J Radiat Oncol Biol Phys. 2017;98(5):1028-35.

9 Linthorst M, Baaijens M, Wiggenraad R, Creutzberg C, Ghidey W, Rhoon GC, et al. Local control rate after the combination of re-irradiation and hyperthermia for irresectable recurrent breast cancer: results in 248 patients. Radiother Oncol. 2015;117:217-22.

10 Fung MC, Schultz DJ, Solin LJ. Early-stage bilateral breast cancer treated with breast-conserving surgery and definitive irradiation: the University of Pennsylvania experience. Int J Radiat Oncol Biol Phys. 1997;38(5): 959-67.

11 Deutsch M. Repeat high-dose external beam irradiation for in-breast tumor recurrence after previous lumpectomy and whole breast irradiation. Int J Radiat Oncol Biol Phys. 2002;53(3):687-91. 